\title{
LOGÍSTICA REVERSA DE EMBALAGENS DE AGROTÓXICOS
}

\section{REVERSE LOGISTICS OF AGROCHEMICALS PACKAGING}

\author{
Miguel Antônio Rodrigues \\ Doutorando em Desenvolvimento e Meio Ambiente na Universidade Federal do Piauí (UFPI) \\ miguel.rodrigues@ifpi.edu.br \\ João Batista Lopes \\ Doutor em Ciências - Energia Nuclear na Agricultura (Universidade de São Paulo, Brasil) \\ Docente do Departamento de Zootecnia e do Programa de Pós-Graduação em Desenvolvimento em Meio \\ Ambiente (UFPI) \\ lopesjb@uol.com.br \\ Elaine Aparecida da Silva \\ Doutora em Desenvolvimento em Meio Ambiente (UFPI) \\ Docente do Departamento de Recursos Hídricos, Geotecnia e Saneamento Ambiental e do Programa de \\ Pós-Graduação em Desenvolvimento em Meio Ambiente (UFPI) \\ elaine@ufpi.edu.br
}

\section{Resumo}

O crescimento da população mundial e os consequentes impactos tem motivado a busca pela eficiência na produtividade, mudando o cenário no meio rural. $\mathrm{O}$ uso de agrotóxicos para melhoria da produtividade tornou-se uma prática comum nas unidades produtoras agrícolas, gerando resíduos que causam impactos ambientais negativos. A sustentabilidade ambiental da agricultura é uma variável de pesquisa indispensável para agentes públicos e privados. Nesse contexto, essa pesquisa teve como objetivo analisar a produção científica, bem como Leis e Decretos acerca da Logística Reversa de embalagens de agrotóxicos. O estudo foi desenvolvido por meio de busca no Portal de Periódicos da CAPES, compreendendo as publicações de 2008 a 2018. Os resultados mostraram que a maior concentração de artigos recuperados corresponde a estudos realizados no Brasil, China, Grécia, República Checa, Colômbia e na Índia, os quais apareceram com maior frequência nos anos de 2013 a 2016, demonstrando que essa abordagem tem se destacado na literatura científica nos últimos anos. Os estudos brasileiros evidenciaram os avanços na produtividade, em função do uso de agrotóxicos, mas destacam os prejuízos que podem causar ao meio ambiente e à saúde do ser humano, associando à necessidade do monitoramento. A poluição dos recursos hídricos, do solo e riscos à saúde humana se destacam nas pesquisas recuperadas. Os trabalhos recuperados apresentam qualidade crítica na análise das consequências do uso arbitrário de agrotóxicos, direcionando para a necessidade de monitoramento constante.

Palavras-chave: Agricultura. Agrotóxicos. Resíduos. Impactos ambientais. Logística reversa.

\begin{abstract}
The growth of the world population and the consequent impacts has motivated the search for efficiency in productivity, changing the scenario in the rural environment. The use of
\end{abstract}


agrochemicals to improve productivity has become a common practice in agricultural production units, generating waste that causes environmental negative impacts. The environmental sustainability of agriculture is an indispensable research kind for public and private agents. In this context, this research aims to analyze the scientific production, as well as Laws and Decrees about Reverse Logistics of agrochemical packaging. The study was carried out by searching the CAPES Periodicals Portal, comprising the publications from 2008 to 2018. The results showed that the highest concentration of articles retrieved corresponds to studies developed in Brazil, China, Greece, Czech Republic, Colombia and India, which appeared most frequently in the years of 2013 to 2016, demonstrating that this approach has been highlighted in the scientific literature in recent years. Brazilian studies showed the advances in productivity, due to the use of pesticides, but highlight the damages they can cause to the environment and human health, associating with the need of monitoring. Pollution of water resources, soil and risks to human health stands out in the researches recovered. The recovered works present critical quality in the analysis of the consequences of the arbitrary use of pesticides, guiding to the necessity of constant monitoring.

Key words: Agriculture. Agrochemicals. Waste. Environmental Impacts. Reverse logistics.

\section{Introdução}

Nas últimas décadas, o setor produtivo vem sendo pressionado para adoção de práticas e políticas ambientais, por meio de iniciativas próprias ou pela imposição de legislação internacional e nacional, na tentativa de amenizar os efeitos negativos da utilização dos recursos naturais e da poluição (MARTINS; SOUZA, 2013).

Essas medidas estão associadas à necessidade de mudança de percepção sobre a realidade ambiental contemporânea, uma vez que os impactos ambientais, em sua maioria, são influenciados pela ação antrópica. Diante disso, são imprescindíveis estudos e ações pautados na racionalidade para o uso e conservação dos recursos naturais, assim como para o gerenciamento dos resíduos e rejeitos resultantes dessa utilização.

Como exemplo, pode-se mencionar a agricultura em larga escala (marcada pelo uso intensivo de tecnologias e agrotóxicos) que, se por um lado, tem possibilitado o atendimento da demanda por alimentos pela população mundial; por outro lado, gera impactos negativos, como a geração de embalagens de agrotóxicos (OLIVEIRA; CAMARGO, 2014).

As práticas e os procedimentos de tratamento para o destino final de embalagens de agrotóxicos, que não estejam regulamentadas por legislação específica, podem promover riscos associados à contaminação do solo e das águas subterrâneas e, ainda, 
problemas potenciais para a saúde das pessoas que as manipulam direta ou indiretamente (WAICHMAN, 2012).

De acordo com o Sistema Nacional de Informações sobre Saneamento - SNIS (2017), a coleta de resíduos sólidos da população rural aponta déficit aproximado de 15 milhões de estabelecimentos sem atendimento, o que corresponde a $47 \%$ do contingente rural do Brasil. Isso mostra a necessidade urgente de que se direcione, por meio de estudos, soluções para o referido quadro.

O artigo 225 da Constituição Federal de 1988 traz a seguinte redação: "Todos têm direito ao meio ambiente ecologicamente equilibrado, bem de uso comum do povo e essencial à sadia qualidade de vida, impondo-se ao Poder Público e à coletividade o dever de defendê-lo e preservá-lo para as presentes e futuras gerações" (BRASIL, 1988). Como expõe a lei maior, preservar o meio ambiente é dever de todos os cidadãos. Assim, é imperativo o apoio da ciência para a mitigação dos impactos negativos à natureza.

Estudo da Organização das Nações Unidas (ONU) revelou que a população global é de, aproximadamente, 7,6 bilhões de habitantes, devendo aumentar para 8,6 bilhões em 2030 (ONU, 2017); o que, de acordo com Diaz-Ambrona e Maletta (2014), deve aumentar a produção de alimentos entre $50 \%$ e $70 \%$.

Nesse contexto, a logística reversa é um instrumento que pode funcionar como um dos meios indutores para o gerenciamento de resíduos e rejeitos de forma sustentável do ponto de vista ambiental, econômico e social; pois, possibilita a destinação e disposição adequada, a revalorização do que é passível de novo aproveitamento, além da participação de toda a sociedade na sua execução.

A logística reversa faz parte das Operações Verdes, no que se refere aos aspectos de coleta, localização e distribuição (BARBIERI et al., 2014). Mais especificamente, a logística reversa das embalagens de agrotóxicos tem sido uma ferramenta importante para a redução de resíduos dispostos de forma inadequada no meio ambiente pelo setor agrícola (OLIVEIRA; CAMARGO, 2014).

No caso das embalagens não reutilizáveis, com a aplicação da logística reversa, devem receber tratamento e disposição adequados para que não degradem o ambiente e/ou não ofereçam risco à saúde humana. Os agrotóxicos são os principais poluentes do modelo da agricultura atual. Os venenos aplicados não afetam somente a área determinada 
para esse fim, geram contaminação dos recursos naturais pelo uso indevido, tornando-se grave problema à saúde pública e ao meio ambiente (OLIVEIRA; SABONARO, 2016).

Desse modo, a abordagem dessa pesquisa é a produção científica, nacional e internacional, além dos dispositivos legais brasileiros relacionados à logística reversa de embalagens de agrotóxicos.

\section{Logística reversa e sua regulamentação}

Antes de abordar sobre a logística reversa, é importante compreender do que se trata a logística convencional ou, simplesmente, logística. Esta, estuda como a administração pode prover melhor nível de rentabilidade nos serviços de distribuição aos clientes e consumidores, por meio de planejamento, organização e controle efetivos para as atividades de movimentação e armazenagem que visam facilitar o fluxo de produtos (BALLOU, 2010).

As atividades de logística tipicamente incluem gestão de transporte de insumos e produtos, gestão de frota, armazenagem e manuseio de materiais, atendimento de pedidos, projeto da rede de instalações, gestão de estoques, planejamento de suprimentos/ demanda e gestão de serviços logísticos (CORREIA; XAVIER, 2013).

A logística reversa, conforme fluxograma apresentado na Figura 1, é considerada instrumento de desenvolvimento sustentável que tem como característica os procedimentos e ações para o fluxo reverso dos resíduos sólidos e/ou rejeitos, para destinação (reutilização/reciclagem) ou disposição final adequada, diminuindo os riscos ao meio ambiente (BRASIL, 2010).

A Política Nacional de Resíduos Sólidos (PNRS), instituída pela Lei $\mathrm{n}^{\circ}$ 12.305/2010, estabelece a logística reversa (BRASIL, 2010), que possui como finalidade o auxílio à conservação do meio ambiente, contribuindo para o desenvolvimento econômico e social, além de agregar valor à imagem corporativa (VALLE; SOUZA, 2014).

Por meio desse instrumento, é incentivado que a responsabilidade pelo ciclo de vida dos produtos seja compartilhada, por meio de um conjunto de atribuições individualizadas e encadeadas dos fabricantes, importadores, distribuidores e comerciantes, dos consumidores e dos titulares dos serviços públicos de limpeza urbana e de manejo dos resíduos sólidos, para minimizar o volume de resíduos sólidos e rejeitos 
gerados, bem como para reduzir os impactos causados à saúde humana e à qualidade ambiental decorrentes do ciclo de vida dos produtos, nos termos da lei (BRASIL, 2010).

Figura 1: Fluxograma do processo de logística reversa

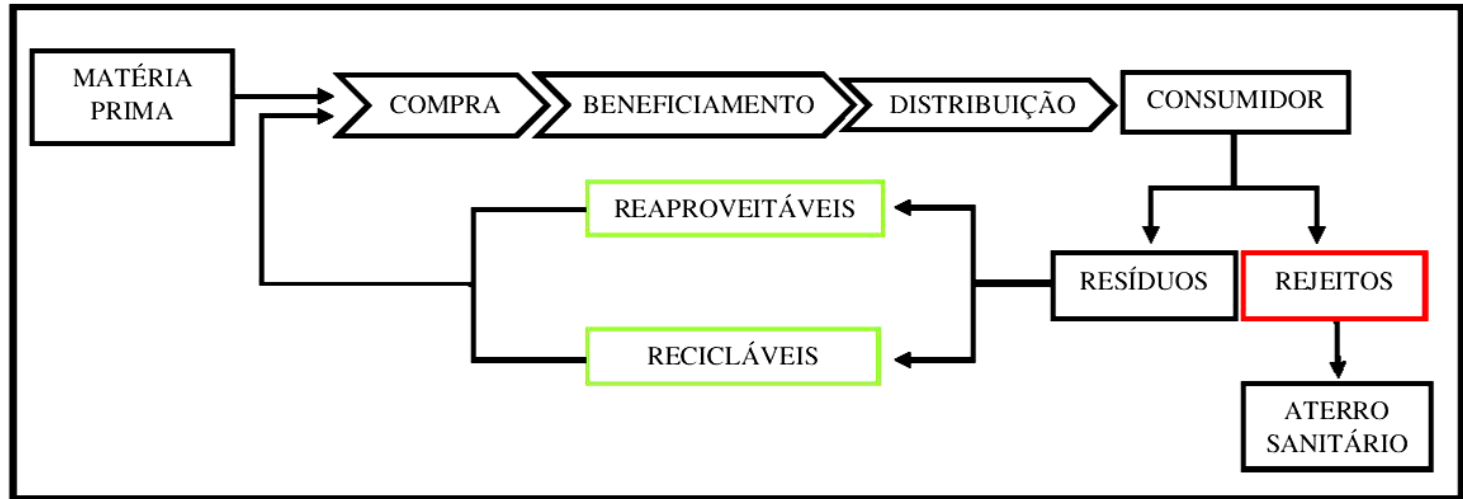

Fonte: Elaborado a partir de BRASIL (2010).

Nesse processo, a logística reversa atua como instrumento de desenvolvimento social e minimização de impactos ambientais; pois, conforme pode-se verificar no fluxograma da Figura 1, a reutilização e/ou reciclagem dos resíduos resulta na economia de matéria prima, à medida que se inicia um novo ciclo de vida do produto. Para os produtos com características de periculosidade, cujo reuso é inviável, faz-se necessário um tratamento prévio, antes de descarte correto em aterros sanitários, possibilitando, assim, a mitigação do impacto ao meio ambiente.

Até a aprovação da Política Nacional dos Resíduos Sólidos, em 2010, a regulamentação legal do uso dos recursos ambientais, com destaque para a prática da aplicação dos agrotóxicos, percorreu um longo caminho, o qual se iniciou em 1981, conforme apresentado na Tabela 1. As preocupações ambientais em nível mundial, demonstradas por meio de Conferências com a participação de autoridades de órgãos com representação internacional foram fundamentais para a concretização do processo de formulação das leis brasileiras, que tratam do meio ambiente.

Na Tabela 1 é evidenciado o quanto o cenário jurídico brasileiro se dedicou à elaboração de Leis, Resoluções e Decretos na busca de regulamentação do uso de agrotóxicos, bem como de determinação de medidas preventivas, que pudessem minimizar os impactos do seu uso. A aprovação desses dispositivos legais foi resultado do aumento da consciência ambiental da população e da pressão exercida por Organizações Não Governamentais (ONGs) ambientalistas, embora sua implementação 
não tenha apresentado a mesma eficiência em todas as Unidades Federativas do território nacional (LADEIRA; MAEHLER; NASCIMENTO, 2012).

Tabela 1: Dispositivos legais brasileiros que regulamentam o uso de agrotóxicos

\begin{tabular}{l}
\hline LEGISLAÇÃO \\
\hline LEI 6.938/1981
\end{tabular}

LEI $7.802 / 1989$

DECRETO 98.816/1990

LEI 9.605/1998

LEI 9.974/2000

DECRETO 3.550/2000

DECRETO 3.694/2000

DECRETO 3.828/2001

DECRETO 4.074/2002

RESOLUÇÃO 334/2003

LEI $12.305 / 2010$

DECRETO 7.404/2010

\section{REGULAMENTA}

Dispõe sobre a Política Nacional do Meio Ambiente, seus fins e mecanismos de formulação e aplicação e dá outras providências.

Dispõe sobre a pesquisa, a experimentação, a produção, a embalagem e rotulagem, o transporte, o armazenamento, a comercialização, a propaganda comercial, a utilização, a importação, a exportação, o destino final dos resíduos e embalagens, o registro, a classificação, o controle, a inspeção e a fiscalização de agrotóxicos, seus componentes e afins e dá outras providências.

Regulamenta a Lei $\mathrm{N}^{\circ}$ 7.802, de 11 de julho de 1989.

Dispõe sobre as sanções penais e administrativas derivadas de condutas e atividades lesivas ao meio ambiente e dá outras providências.

Altera a Lei 7.802, de 11 de julho de 1989 e regulamenta a obrigatoriedade do recolhimento das embalagens pelas empresas produtoras e comercializadoras de agrotóxicos.

Dá nova redação aos dispositivos do Decreto ${ }^{\circ} 98.816$, de 11 de janeiro de 1990.

Altera e inclui dispositivos ao Decreto n ${ }^{\circ} 98.816$ de 11 de janeiro de 1990.

Altera e inclui dispositivos ao Decreto ${ }^{\circ} 98.816$ de 11 de janeiro de 1990 , que dispõe sobre o controle e a fiscalização de agrotóxicos e dá outras providências.

Regulamenta a Lei $\mathrm{n}^{\circ} 7.802$, de 11 de julho de 1989.

Dispõe sobre os procedimentos de licenciamento ambiental de estabelecimentos destinados ao recebimento de embalagens vazias de agrotóxicos.

Institui a Política Nacional de Resíduos Sólidos; altera a Lei nº 9.605, de 12 de fevereiro de 1998; e dá outras providências.

Regulamenta a Lei ${ }^{\circ} 12.305$, de 2 de agosto de 2010, que institui a Política Nacional de Resíduos Sólidos, cria o Comitê Interministerial da Política Nacional de Resíduos Sólidos e o Comitê Orientador para a Implantação dos Sistemas de Logística Reversa, e dá outras providências.

Fonte: Elaborado com base nos dispositivos legais.

Desse modo, são diversas as consequências negativas resultantes das falhas no sistema de aplicação, manuseio e/ou não estabelecimento da logística reversa das embalagens dos defensivos agrícolas. É necessário considerar a complexidade da atividade, associada à obrigatoriedade de atualização dos dispositivos legais à medida que novas tecnologias e/ou procedimentos são adotados, por se tratar de um processo com 
mudanças contínuas, uma vez que seu uso visa controlar variáveis da natureza e esta não oferece previsibilidade.

$\mathrm{Na}$ atuação do Instituto Nacional de Processamento de Embalagens Vazias (INPEV) no recebimento e tratamento de embalagens de agrotóxicos da agricultura brasileira (Tabela 2), é ressaltado que mais de $90 \%$ das embalagens recebidas foram para a reciclagem e as demais, pela natureza dos produtos que armazenavam, foram incineradas. O Brasil é o maior consumidor mundial de defensivos agrícolas. Somente na safra de 2013/2014, foram consumidos cerca de um bilhão de litros de agrotóxicos (INPEV, 2017), o que evidencia a ausência do retorno de suas embalagens na íntegra, quando se analisa os números da Tabela 2. Por esse motivo, os resíduos de agrotóxicos ainda escorrem para córregos e lençóis freáticos (LOPES et al., 2017), causando impactos ambientais que comprometem a biodiversidade e também a saúde humana.

Tabela 2: Embalagens recicladas e incineradas pelo INPEV

\begin{tabular}{cccc}
\hline Ano & Reciclagem & Incineração & Total \\
& & & \\
\hline 2013 & 37.196 & 3.207 & 40.403 \\
2014 & 38.795 & 3.650 & 42.645 \\
2015 & 41.084 & 4.453 & 45.537 \\
\hline
\end{tabular}

Por outro lado, em comparação com outros países, o Brasil destaca-se no destino correto de embalagens de defensivos agrícolas, após o recebimento nas unidades, como se pode verificar na Figura 2. Das embalagens de agrotóxicos utilizadas na agricultura do Brasil que retornam às unidades de recebimento, 94\% tem descarte adequado (INPEV, 2017). É importante mencionar que o INPEV não apresenta esclarecimentos de como essas informações foram obtidas.

De acordo com a Agência Nacional de Vigilância Sanitária - ANVISA (2013), enquanto o crescimento do uso de agrotóxicos no mundo aumentou quase $100 \%$ entre os anos de 2000 e 2009, no Brasil esta taxa atingiu quase 200\%, situação preocupante que direciona para estudos e ações que venham a moderar os efeitos potenciais desses produtos.

$\mathrm{O}$ armazenamento inadequado de pesticidas e o descarte de resíduos, bem como a proteção pessoal inadequada durante o manuseio e a aplicação de pesticidas foram 
difundidos, com pouca consciência de risco geral para a saúde humana e ambiental (CHAU et al., 2015).

Figura 2: Ranking mundial dos principais países que se destacam no destino correto de embalagens de agrotóxicos

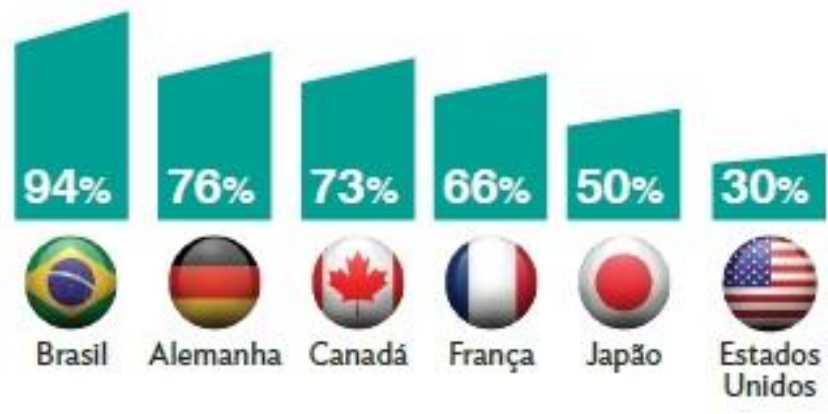

Fonte: INPEV (2017).

O INPEV reconhece a necessidade de cuidados com o manuseio das embalagens de agrotóxicos, ao apontar saúde e segurança como prioridade em seu relatório de sustentabilidade do ano de 2016. Para tanto, reforçou a atenção a esse pilar nas centrais de gerenciamento próprio e orientou as demais unidades a adotarem as melhores práticas (INPEV, 2017).

\section{Material e métodos}

Inicialmente, realizou-se a busca dos dispositivos legais que regulamentam o uso de agrotóxicos, no Brasil, seguida de análise dos dados disponíveis no Instituto Nacional de Processamento de Embalagens Vazias (INPEV), bem como no Sistema Nacional de Informações sobre Saneamento (SNIS). Após a análise desses dados, foi feita busca do tema em estudo no Portal de Periódicos da Coordenação de Aperfeiçoamento de Pessoal de Nível Superior (CAPES).

Através da análise bibliométrica foi possibilitado o mapeamento da produção científica sobre logística reversa associada às embalagens de agrotóxicos, publicada no período de 2008 a 2018.

Assim, foi possível analisar discussões acerca da temática, haja vista a grande quantidade de artigos disponíveis em periódicos de diversos países. Estão disponíveis 38 mil publicações periódicas internacionais e nacionais (CAPES Portal de Periódicos/MEC, 
2018). O portal garante a realização de pesquisa em conhecimentos de diversas áreas, pois reune 134 bases de dados.

A pesquisa foi realizada utilizando-se os termos "reverse logistics" OR "inverse logistics" AND agriculture / "reverse logistics" OR "inverse logistics" AND pesticide / agrochemical AND "reverse logistics" e "pesticide waste". A utilização dos termos na língua inglesa possibilitou maior abrangência ou alcance da literatura científica internacional.

Ao pesquisar os termos "reverse logistics" OR "inverse logistics" and agriculture, foram recuperados 245 trabalhos (Tabela 3), dos quais 20\% são artigos que tratam da temática em pesquisa. Os outros $80 \%$ são artigos que tratam da logística reversa de outros produtos, como eletro eletrônicos, pneus e agricultura, em geral, e foram recuperados porque mencionavam, pelo menos uma vez, os termos pesquisados. Assim, para esta busca, foram analisados $20 \%$ dos artigos recuperados, haja vista que os demais abordavam temáticas correlatas, mas que que não contemplavam o foco da pesquisa.

Com os termos "reverse logistics" or "inverse logistics" and pesticide, recuperouse 38 resultados, dos quais 50\% são artigos que não estavam no escopo da temática em estudo (Tabela 3). Os demais 50\% são artigos repetidos, fazendo parte da lista dos artigos recuperados nos $50 \%$ já mencionados ou na busca feita com os termos "reverse logistics" or "inverse logistics" and agriculture, e também que tratam da logística reversa de outros produtos, como pneus de veículos, o que direcionou para a análise apenas dos 50\% que corresponderam ao escopo do tema central.

Tabela 3: Publicações científicas que abordam logística reversa e agrotóxicos

\begin{tabular}{|c|c|c|}
\hline Termos Pesquisados & $\begin{array}{l}\text { Quantidade } \\
\text { recuperada }\end{array}$ & $\begin{array}{l}\text { Quantidade } \\
\text { selecionada }\end{array}$ \\
\hline $\begin{array}{l}\text { "Reverse logistics" OR "inverse logistics" } \\
\text { AND agriculture }\end{array}$ & 245 & 49 \\
\hline $\begin{array}{l}\text { "Reverse logistics" OR "inverse logistics" } \\
\text { AND pesticide }\end{array}$ & 38 & 19 \\
\hline Agrochemical AND "reverse logistics" & 05 & 03 \\
\hline "Pesticide waste" & 137 & 103 \\
\hline
\end{tabular}

Fonte: Elaborado a partir do Portal de Periódicos Capes (2018). 
$\mathrm{Na}$ pesquisa dos termos agrochemical and "reverse logistics", recuperou-se 05 resultados (Tabela 3), dos quais $60 \%$ são artigos que tratam da temática em pesquisa. Os outros $40 \%$ tratam da logística reversa de eletro eletrônicos.

A busca feita com o termo "Pesticide waste" foi a que apresentou mais resultados satisfatórios inseridos no tema pesquisado; dos 137 resultados recuperados (Tabela 3), 103 (cerca de 75\%) tratavam do uso dos agrotóxicos na agricultura, dos seus impactos ao meio ambiente, ou da busca eficiência na produtividade agrícola com o uso de defensivos agrícolas.

\section{Resultados e discussão}

Foram analisados 174 artigos científicos, considerando-se a pesquisa dos termos "reverse logistics" OR "inverse logistics" AND agriculture, "reverse logistics" OR "inverse logistics" AND pesticide, agrochemical AND "reverse logistics" e "pesticide waste", o que correspondeu a 40,9\% do total dos 425 recuperados. Os artigos foram selecionados fundamentando-se na abordagem do tema central da pesquisa.

Embora o período de busca contemple as publicações de 2008 a 2018, os artigos recuperados que tratam do tema em estudo são relativos ao período 2011-2017, com destaque para 2013, 2014, 2015 e 2016 (Figura 3). No tocante aos países com maior destaque para publicação de artigos voltados para o uso de agrotóxicos e/ou logística reversa de suas embalagens, o Brasil contabilizou 15,5\% das publicações, seguido da China, com 11,5\%, Grécia, 11,0\%, República Checa, 9,2\%, Colômbia, 8,6\% e Índia, 8\%.

Outros países como Polônia, Espanha, Etiópia, México, Omã, Venezuela, Tanzânia, Costa Rica, Malásia e Ucrânia aparecem na busca com menor frequência relativa (Figura 3).

Nos países que mais se destacaram na busca, os artigos abordam temáticas genéricas associadas aos agrotóxicos, seu uso, descarte de embalagens, legislação, bem como resultados de pesquisas mais específicas, que apontam e refletem as consequências da utilização.

No Brasil, os estudos apontam os avanços na produtividade em função do uso dos agrotóxicos, necessidade de monitoramento, o ônus para o meio ambiente e, consequentemente, para a sociedade, principalmente vinculando essa prática à 
contaminação de corpos de água doce, com efeitos negativos à saúde humana. E a logística reversa das embalagens de defensivos agrícolas é apresentada como uma ferramenta mitigadora desses impactos (PEREIRA; ARAÚJO; LABINAS, 2016).

Figura 03: Número de artigos publicados sobre logística reversa de embalagem de agrotóxicos, associado aos países e ano de publicação

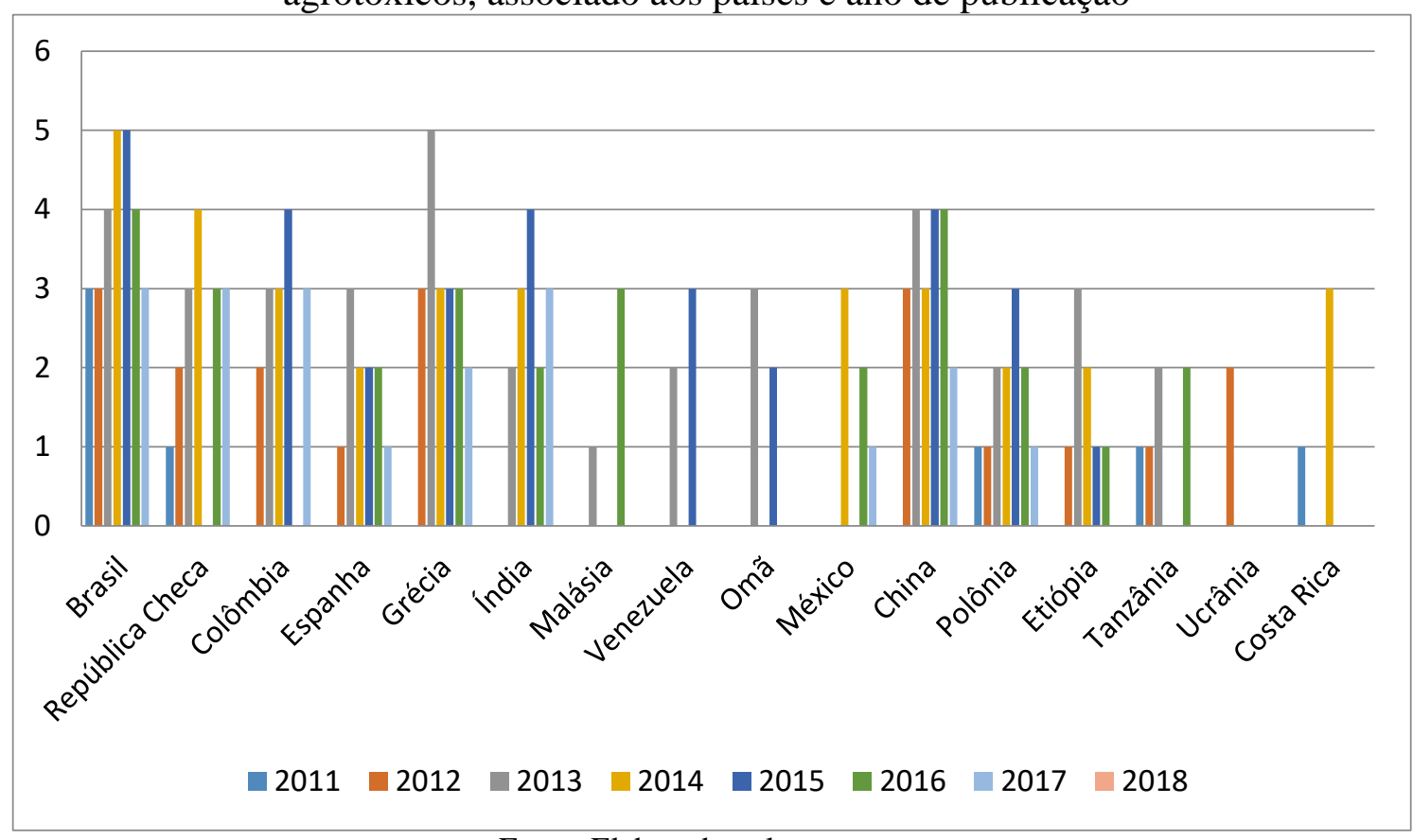

Fonte: Elaborado pelos autores.

Nesse contexto, é pertinente destacar que após a estabilização da Revolução Verde, denominação dada à modernização agrícola que amplificou o cultivo agro econômico a partir da década de 1970, a produtividade agrícola modificou-se, principalmente em países capitalistas, em estruturas monocultoras e dependentes de agrotóxicos (RICO; CAVICHIOLI, 2018), como é o caso do Brasil.

O uso indiscriminado dos agrotóxicos, no Brasil, é resultado da busca pelo acúmulo de capital que direciona práticas voltadas para o aumento da produtividade, bem como para a expansão da produção agrícola para regiões cujo solo permite uma adaptação para o cultivo de grãos em larga escala e, com isso, multinacionais passam a investir nessas regiões, visando expandir suas atividades. É o caso do que ocorreu com o Cerrado Piauiense, cujas terras, a princípio, eram consideradas improdutivas, mas a partir de pesquisas realizadas pela Empresa Brasileira de Pesquisa Agropecuária (Embrapa), tornaram-se alvo de empreendedores agrícolas tradicionais da região Sul do País. 
De acordo com o Instituto de Pesquisa Econômica Aplicada (IPEA, 2018), o progresso da produtividade de grãos foi decorrente da utilização dos insumos nas lavouras, o que possibilitou que a área cultivada no Brasil tivesse uma expansão de 32,7 milhões de hectares, bem como o consumo de fertilizantes passou de 2,0 milhões de toneladas para 15 milhões, entre 1975 a 2016. Nesse mesmo período, a produção de grãos passou de 40,6 milhões de toneladas para 187,0 milhões de toneladas (IPEA, 2018).

Com essa expansão, o Brasil passou a ser o país agrícola com o maior consumo de agrotóxicos do mundo desde 2008 (VEIGA, 2013). O crescimento no consumo e, consequentemente, no seu uso, tem sido intenso, atingindo em 2015 um total de 887.872 toneladas de produto comercial (SINDIVEG, 2016); a contaminação pelo seu uso pode ocorrer por meio do ar, vento, chuvas, penetração no solo e assim através da água subterrânea, dos alimentos contaminados (DUTRA; SOUZA, 2017). Nesse sentido, o destino de suas embalagens necessita de um direcionamento pontual, tendo em vista o alto grau de toxicidade das substâncias armazenadas. Por isso, a legislação brasileira exige o seu gerenciamento adequado.

Com a criação do Instituto Nacional de Processamento de Embalagens Vazias, em 2001, o descarte adequado de embalagens de agrotóxicos, bem como o reaproveitamento tornaram-se mais eficientes, pois esse instituto atua de forma articulada com os demais agentes da cadeia de logística reversa de embalagens: fabricantes, agricultores e governo (LABINAS; ARAÚJO, 2016). Entre esses agentes, o compartilhamento das ações e atividades ocorrem tanto em nível operacional, a exemplo do tratamento, armazenamento e transporte das embalagens, como em nível estratégico, como em ações que privilegiam a conscientização da sociedade quanto à importãncia de de se fazer o uso adequado dos agrotóxicos, as medidas preventivas do seu manuseio adequado e descarte de embalagens.

$\mathrm{Na}$ China, as pesquisas abordam a preocupação com poluição dos recursos hídricos e do solo nas áreas agrícolas do país, tendo uso de agrotóxicos como a sua principal causa. É evidenciada a preocupação com a falta de legislação adequada, pouca conscientização dos consumidores, além do pouco preparo dos produtores para manuseio de produtos que ofereçam risco à saúde, à segurança e proteção do meio ambiente (MANOMAIVIBOOL; VASSANADUMRONGDEE, 2011; WANG et al., 2012).

Os estudos recuperados da Grécia, onde cerca de $20 \%$ da força de trabalho da população é aplicada na agricultura, abordam os efeitos do uso de agrotóxicos na saúde e 
segurança da população agrícola, a qual sofre impactos negativos pela exposição aos defensivos agrícolas (ARCURY; QUANDT, 2011).

Na República Checa, além dos estudos mostrarem os efeitos potenciais dos agrotóxicos à saúde humana, destaca-se as barreiras encontradas pelos produtores no tratamento das embalagens, pois não há preparo técnico, além disso, a logística reversa é vista como atividade secundária (ŠKAPA, 2011). Na Colômbia, a logística reversa encontra barreiras associadas à falta de integração entre os agentes da cadeia, além de evidenciar a falta de treinamento dos produtores (RODRÍGUEZ; DAVID, 2017). Na Índia, destacaram-se os efeitos positivos do uso dos agrotóxicos na produção agrícola em larga escala, mas ficou evidente o baixo nível de importância da cadeia de logística reversa em comparação com outras atividades (GORANE; KANT, 2016).

De acordo com Veiga (2013), apesar do sucesso agregado, o programa de logística reversa não se apresentou eficiente para pequenas comunidades rurais brasileiras, uma vez que na visão do autor não é possível usar a mesma estratégia logística para comunidades pequenas e grandes. Assim, ele pondera que a reciclagem pode não se constituir a solução ideal, especialmente, para países em desenvolvimento com infraestrutura de reciclagem insatisfatória e, também, por apresentar elevados custos de transporte.

Neste contexto, a difusão dos agrotóxicos, apesar de acompanhar e contribuir com os avanços tecnológicos e produtivos dos cultivos, vem resultando em elevado ônus para a sociedade, com destaque para problemas de saúde da população e do meio ambiente (GODECKE; TOLEDO, 2015). Com relação aos problemas potenciais vinculados à saúde humana, Boemo et al. (2015) destacam que devido ao estilo de vida mais saudável, associado a hábitos de consumo, bem como à atividade física mais intensiva dos agricultores do distrito de Santa Flora, no Rio Grande do Sul, Brasil, esperava-se que eles apresentassem menor frequência de problemas de saúde. No entanto, os agricultores apresentam distúrbios nas orelhas, nariz e garganta, provocados, dentre outros fatores, pela exposição a agrotóxicos. Para esses autores, o número de abortos relatados entre as mulheres agricultoras é superior ao das não agricultoras; esta constatação pode estar associada à exposição das agricultoras a agrotóxicos.

No âmbito da análise de impactos negativos causados pelo uso de agrotóxicos na agricultura, Puche (2013) destaca que a aceitação destes produtos ocorre em função da estrutura do mercado em nível mundial, dominado por poucas empresas, as quais utilizam 
seu poderio econômico para influenciar na aprovação de novos produtos, que periodicamente são lançados no mercado.

Nesse sentido, os motivos para o crescimento do emprego da logística reversa são os mais diversificados: os produtores tentam se inserir em um mercado que exerce pressão sobre as companhias, devido ao fato de os consumidores exigirem produtos com custos mais baixos e, ao mesmo tempo, que causem menor dano ao meio ambiente. Por outro lado, existem as questões legais, que aumentam em quantidade e complexidade e tornamse incentivos para que a empresa gerencie completamente o ciclo de vida de seus produtos (SHIMBÃO; MOORI; SANTOS, 2010).

Assim, a caracterização das unidades produtoras, que utilizam agrotóxicos na sua produção, torna-se relevante para o meio técnico e produtivo, com a perspectiva de se direcionar ações políticas, as quais visem maximizar práticas sustentáveis no campo. Outro aspecto relevante, diz respeito à rastreabilidade total como mecanismo eficaz na efetividade do cumprimento dos dispositivos legais pelos agentes da cadeia, uma vez que a lei brasileira exige o retorno de recipientes de agrotóxicos, seguido da implementação de um sistema de logística reversa, envolvendo diferentes partes interessadas, tais como produtores de agrotóxicos, agricultores e governos, em que cada um tem papel importante a desempenhar para que o sistema seja efetivo (BRASIL, 2010).

Santos et al. (2013), em estudo sobre gerenciamento de materiais em uma empresa de álcool e açúcar, apontam a melhoria da eficiência da produtividade da agricultura global em função da adoção de tecnologias e uso de agrotóxicos, mas ponderam, ao mencionar que esse pacote tecnológico traz muitos problemas ambientais, especialmente em relação aos danos causados pelos pesticidas associados ao descarte inadequado de seus pacotes.

Em consonância com pesquisas que afirmam haver inconsistência no gerenciamento das embalagens de agrotóxicos, Bernardo et al. (2015), em estudo sobre a percepção de produtores rurais acerca da legislação que regulamenta o tema, em Tupã/SP, afirmam que cerca de $60 \%$ dos respondentes são indiferentes, conhecem muito pouco ou desconhecem sua responsabilidade como primeiro elo da cadeia da logística reversa das embalagens vazias de agrotóxicos. Este achado se torna preocupante, dada a importância dos produtores rurais no gerenciamento das embalagens. 
Apesar da relevância do assunto, tanto para o meio ambiente quanto à saúde humana, percebe-se que a temática não recebeu muita atenção nas investigações, que contribuem para a melhoria deste processo. Logo, existem poucas publicações que visam avaliar ou projetar processos de coleta, tratamento e disposição final de recipientes de pesticidas sob padrões de qualidade e sempre mitigando o impacto negativo sobre o meio ambiente (CASTAÑEDA; RODRÍGUEZ, 2014), o que se pode constatar a partir da bibliometria realizada nessa pesquisa, a qual, mesmo utilizando as palavras-chave que contemplam o escopo da logística reversa de embalagem de agrotóxicos (Tabela 3), dos 174 artigos analisados apenas cerca de $10 \%$ estão direcionados para uma análise holística do processo da logística reversa.

Na Colômbia, Silva e Contreras (2015) e Castañeda et al. (2013) relataram o problema da gestão e tratamento inadequado dos resíduos de embalagens de agrotóxicos pelos agricultores. Ainda, Silva e Contreras (2015) fizeram uma simulação do processo atual, visando a criação de dois cenários possíveis para a operação de recursos humanos e físicos nesse processo, e assim, propuseram uma configuração viável, que proporcionou a maior redução no tempo de coleta dos resíduos, apontando melhoria de $46 \%$ no tempo total que o processo pode ser alcançado. Nesse mesmo país, estudo realizado por Castañeda et al. (2013) evidenciou que os atores envolvidos no processo de coleta e disposição final de resíduos de agrotóxicos não estão em conformidade com os regulamentos, aparentando falhas no manuseio e descarte. Desta forma, se observa que o processo, atualmente, realizado é empírico e não leva em consideração atividades de logística reversa.

Em estudo realizado por Rodríguez e David (2017), na Colômbia, constatou-se que há falta de informações e treinamento que orientem os agricultures acerca do processo de tratamento e coleta das embalagens de agrotóxicos, o que para Klapalová (2013) representa a maior barreira para a implantação com êxito de um sistema de logística reversa, visto que o conhecimento e a consciência sobre a logística reversa são os passos iniciais para o prosseguimento das atividades.

$\mathrm{Na}$ fase de coleta, observa-se que a maioria dos agricultores não entrega seus resíduos classificados, incorrendo no descumprimento dos regulamentos vigentes, razão pela qual, treinamento e maior supervisão no manejo de resíduos perigosos devem ser realizados (RODRÍGUEZ; DAVID, 2017). Nessa sequência, destaca-se um estudo 
desenvolvido na Venezuela, que aponta a necessidade da logística reversa em setores produtivos como agricultura e serviços (GARCÍA-RODRÍGUEZ et al., 2013). Nessas atividades, pode-se observar a baixa adoção dessa ferramenta pelo meio produtivo, apesar dos fatores favoráveis, considerando-se as relações de mercado altamente competitivo, marcadas pelos processos de produção e compras serem favoráveis ao meio ambiente em uma dimensão universal (MILICHOVSKÝ, 2017).

Em estudo desenvolvido por Gorane e Kant (2016), na Índia, em que foi investigado o nível de alcance de práticas da Cadeia de Suprimentos nas Organizações, classificando variáveis com alto, moderado e baixos níveis de presença nas atividades, a logística reversa posicionou-se no grupo de práticas menos penetradas nas empresas.

Segundo Škapa (2011), na República Checa, a principal barreira interna do desenvolvimento da logística reversa diz respeito à pouca importância em comparação com outras atividades, seguido da falta de gerenciamento sistemático e força de trabalho não qualificada. A capacidade de reconhecer diferentes conexões de fluxos reversos nos negócios (oportunidades, ameaças e pontos fortes e fracos) é um dos fatores importantes que afetam o avanço da logística reversa (ŠKAPA, 2014).

No âmbito da importância dada ao fluxo reverso das atividades em empresas nesse mesmo país, Klapalová (2012) destaca que existem diferenças significativas entre as empresas que planejam a logística reversa de forma estratégica e aquelas que a planejam apenas nos níveis tático e operacional. Também, existem aquelas que não planejam de forma alguma. Tem-se constatado que empresas que terceirizam a atividade percebem menos benefícios financeiros do que aquelas que incluem na cadeia da própria empresa, direcionando também para o entendimento de que nas maiores empresas, os benefícios dessa prática são potencializados, haja vista os resultados na agregação de valor aos produtos.

Os resultados das atividades de logística reversa implicam nas três dimensões do desenvolvimento sustentável: econômica, social e ambiental (GOVINDAN; PAAM; ABTAHI, 2016), apesar de que a seleção de várias opções reversas de disposição de produtos de logística depende do valor residual dos produtos e da acessibilidade de conteúdo reutilizável para reentrada na cadeia de fornecimento direta (KHOR; UDIN, 2013). 
No Brasil, estudo desenvolvido por Pereira, Araújo e Labinas (2016) mostrou que produtores rurais foram capazes de reconhecer as normas gerais que envolvem o uso dos agrotóxicos, porém ainda apresentam dificuldades nas aplicações práticas referentes ao armazenamento na propriedade rural e na logística de devolução das embalagens vazias.

A gestão sustentável concentra-se na melhoria da eficiência dos nutrientes e na gestão de resíduos. Logo, a agricultura sustentável deve introduzir um modelo de economia circular e uma logística reversa para gerenciamento de resíduos (DIAZAMBRONA; MALETTA, 2014).

\section{Considerações finais}

O Brasil possui destaque mundial no consumo de agrotóxicos e, neste cenário, os dispositivos legais, em nível nacional, sobre o uso e manuseio dos mesmos e suas embalagens também ganharam espaço. A logística reversa é um instrumento que visa auxiliar o gerenciamento adequado das referidas embalagens, no Brasil e em outros países nos quais foram identificadas pesquisas sobre o conteúdo neste trabalho. Entretanto, verificou-se dificuldades que comprometem a sua aplicação e fazem com que os produtores não o compreendam de forma sistêmica, e isso repercute na atuação de um dos agentes mais importantes da cadeia: o agricultor.

A maior concentração de artigos recuperados sobre a temática tem como origem Brasil, China, Grécia, República Checa, Colômbia e na Índia. Aparecem, também, na pesquisa, mas com menor frequência, estudos sobre esta temática realizados na Polônia, Espanha, Etiópia, México, Omã, Venezuela, Tanzânia, Costa Rica, Malásia e Ucrânia.

De modo geral, as pesquisas mostraram que as atividades de fluxo reverso das embalagens de agrotóxicos fazem parte do cotidiano das unidades de produção agrícolas, porém apresentam limitações quanto ao nível de informações que chegam ao produtor, no que tange à rotina do manuseio das embalagens dos diferentes tipos de defensivos agrícolas.

As tendências das pesquisas convergem para a necessidade de atenção ao manuseio dessas embalagens, uma vez que os efeitos das substâncias contidas nestes recipientes podem se espalhar na natureza, transcendendo as fronteiras da área demarcada para sua aplicação e causando danos à saúde das pessoas e ao meio ambiente. 
Apesar dos trabalhos recuperados apresentarem qualidade relacionada à crítica na análise das consequências do uso de agrotóxicos, é necessário que sejam realizadas mais pesquisas com abordagem no monitoramento de seu uso, efeitos de longo prazo, identificação de alternativas mais sustentáveis ambientalmente, além da indicação de caminhos que levem à efetividade da aplicação de instrumentos, como a logística reversa.

\section{Referências}

AGÊNCIA NACIONAL DE VIGILÂNCIA SANITÁRIA (ANVISA). Programa de Análise de Resíduos de Agrotóxicos em Alimentos (PARA): Relatório de Atividades de 2011 e 2012. Gerência-Geral de Toxicologia. Brasília, 29 de outubro de 2013.

ARCURY T., QUANDT S. A. Viver e trabalhar de forma segura: desafios para os trabalhadores agrícolas migrantes e sazonais. NC Med. J. 2011; 72: 466-470.

BALLOU, Ronald H. Logística empresarial, transportes, administração de materiais, distribuição física. 1. Ed. São Paulo: Atlas, 2010.

BARBIERI, J. C.; SOUSA FILHO, J. M. de; BRANDÃO, C. N.; Di Serio, L. C. ; REYES JUNIOR, E. Gestão verde da cadeia de suprimentos: análise da produção acadêmica brasileira, Revista Produção Online, 2014, Florianópolis, SC, v.14, n. 3, p. 1104-1128.

BERNARDO, C. H. C.; BRAGA JÚNIOR, S. S.; MARQUES, M. D.; GOMES, S. C. V.; QUEIROZ, T. R. Percepção dos produtores rurais de Tupã, SP, sobre o processo de comunicação para execução da logística reversa de embalagens de agrotóxicos. Revista Observatório, 2015, Vol.1(3), pp.242-270.

BOEMO, R. V; DENARDIN, E. S.; MEDEIROS, N. C. L.; MEDEIROS, F. S. B.; PIVETA, M. N. The process of reverse logistics as a practice of preserving the environment: the case of agricultural producers in the District of Santa Flora/RS.

Revista eletrônica em gestão, educação e tecnologia, 2015, V. 19, p. 339-350.

BRASIL. Ministério do Meio Ambiente. Logística reversa. 2017. Disponível em: $<$ http://www.mma.gov.br/cidades-sustentaveis/residuos-solidos/instrumentos-dapolitica-de-residuos/comite-orientador-logistica-reversa>. Acesso em: 16 mai. 2017.

BRASIL. Ministério das Cidades. Secretaria Nacional de Saneamento Ambiental (SNSA). Sistema Nacional de Informações sobre Saneamento: Diagnóstico do Manejo de Resíduos Sólidos Urbanos - 2015. - Brasília: MCIDADES.SNSA, 2017. 173 p.: gráficos, tabelas.

BRASIL. Lei ${ }^{\circ}$ 6.938, de 31 de agosto de 1981. Dispõe sobre a Política Nacional do Meio Ambiente, seus fins e mecanismos de formulação e aplicação e dá outras 
providências. Diário Oficial da República Federativa do Brasil, Brasília, 1 Setembro 1981.

BRASIL. Constituição (1988). Constituição da República Federativa do Brasil. Brasília, DF: Senado Federal: Centro Gráfico, 1988. 292 p.

BRASIL. Lei $\mathrm{n}^{\circ}$ 7.802, de 11 de julho de 1989. Lei dos Agrotóxicos. Diário Oficial da República Federativa do Brasil, Brasília, DF, 12 Julho 1989.

BRASIL. Decreto n ${ }^{\circ}$ 98.816, de 11 de janeiro de 1990. Regulamenta a Lei No 7.802 , de 11 de julho de 1989. Diário Oficial da República Federativa do Brasil, Brasília, DF, 12 Janeiro 1990.

BRASIL. Lei $n^{\circ}$ 9.605, de 12 de fevereiro de 1998. Dispõe sobre as sanções penais e administrativas derivadas de condutas e atividades lesivas ao meio ambiente, e dá outras providências. Diário Oficial da República Federativa do Brasil, Brasília, DF, 13 Fevereiro 1998.

BRASIL. Decreto ${ }^{\circ} 3.550$, de 27 de julho de 2000. Dá nova redação a dispositivos do Decreto ${ }^{\circ}$ 98.816, de 11 de janeiro de 1990. Diário Oficial da República Federativa do Brasil, Brasília, DF, 28 Julho 2000.

BRASIL. Decreto ${ }^{\circ}$ 3.694, de 21 de dezembro de 2000. Altera e inclui dispositivos ao Decreto ${ }^{\circ} 98.816$ de 11 de janeiro de 1990. Diário Oficial da República Federativa do Brasil, Brasília, DF, 22 Dezembro 2000.

BRASIL. Lei ${ }^{\circ} 9.974$, de 6 de junho de 2000. Altera a Lei $\mathrm{N}^{\circ} 7.802$, de 11 de julho de 1989. Diário Oficial da República Federativa do Brasil, Brasília, DF, 7 Junho 2000.

BRASIL. Decreto n $^{\mathrm{o}} 3.828$, de 31 de maio de 2001. Altera e inclui dispositivos ao Decreto no 98.816, de 11 de janeiro de 1990, que dispõe sobre o controle e a fiscalização de agrotóxicos e da outras providências. Diário Oficial da República Federativa do Brasil, Brasília, DF, 1 Junho 2001.

BRASIL. Decreto $n^{\circ} 4.074$, de 4 de janeiro de 2002. Regulamenta a Lei no 7.802, de 11 de julho de 1989. Diário Oficial da República Federativa do Brasil, Brasília, DF, 5 Janeiro 2002.

BRASIL. Resolução CONAMA nº 334, de 3 de abril de 2003. Dispõe sobre os procedimentos de licenciamento ambiental de estabelecimentos destinados ao recebimento de embalagens vazias de agrotóxicos. Diário Oficial da República Federativa do Brasil, Brasília, DF, 19 maio de 2003.

BRASIL. Decreto ${ }^{\circ} 7.404$, de 23 de dezembro de 2010. Regulamenta a Lei $\mathrm{n}^{\circ}$ 12.305, de 2 de agosto de 2010. Diário Oficial da República Federativa do Brasil, Brasília, DF, 24 Dezembro 2010. 
BRASIL. Lei $\mathrm{n}^{\mathrm{o}}$ 12.305, de 2 de agosto de 2010. Institui a Política Nacional de Resíduos Sólidos; altera a Lei no 9.605, de 12 de fevereiro de 1998; e dá outras providências. Diário Oficial da República Federativa do Brasil, Brasília, DF, 3 Agosto 2010.

CASTAÑEDA, E. D. C.; RODRÍGUEZ, J. D. S. Logística inversa usando simulacion en la recolección de envases de plaguicidas: estado del arte. Ingenieria Industrial, 2014, V. 13(1), pp 33-50.

CASTAÑEDA, E. D. C.; DIONISIO, E.; BENÍTEZ, F.; MERCEDES, A.; RODRÍGUEZ, J. D.; DAVID, J. Diseño de un sistema de logística inversa para la recolección de envases y empaques vacíos de plaguicidas. Revista Ingeniería Industrial, 2013, Vol.12 (2), p.29-43.

CHAU, N. ; SEBESVARI, Z. ; AMELUNG, W. ; RENAUD, F. Pesticide pollution of multiple drinking water sources in the Mekong Delta, Vietnam: evidence from two provinces. Environmental Science and Pollution Research, 2015, Vol.22(12), pp. 9042-9058.

CORREIA, H. L.; XAVIER, L. H.;. Concepts, design and implementation of Reverse Logistcs Systems for Sustainable Supply Chains in Brazil. Journal of Operations and Supply Chain Management, 2013, Vol.6(1), pp.1-25.

DIAZ-AMBRONA, C. G. H.; MALETTA, E. Achieving Global Food Security through Sustainable Development of Agriculture and Food Systems with Regard to Nutrients, Soil, Land, and Waste Management. Current Sustainable/Renewable Energy Reports, 2014, Vol.1(2), pp.57-65.

DUTRA, R. M. S.; SOUZA, M. M. O. de. Cerrado, revolução verde e evolução do consumo de agrotóxicos. Sociedade \& Natureza, vol. 29, n. 3, 2017, pp. 473-488. Disponível em: https://www.redalyc.org/pdf/3213/321355044008.pdf. Acesso em: 09 mai. 2019.

GARCÍA-RODRÍGUEZ, F. J.; CASTILLA-GUTIÉRREZ, C.; BUSTOS-FLORES, C. Implementation of reverse logistics a sustainable tool for raw material purchasing in developing countries: The case of Venezuela. International Journal of Production Economics, 2013, Vol.141(2), pp.582-592.

GODECKE, M. V; TOLEDO, E. R. M. S. Logística reversa de embalagens de agrotóxicos: estudo do caso de pelotas/RS. Revista Meio Ambiente e Sustentabilidade, 2015, vol.9, n.4, p. 220-242.

GORANE, S. J; KANT, R. Supply chain practices. Benchmarking: An International Journal, 2016, Vol.23(5), pp.1076-1110.

GOVINDAN, K.; PAAM, P.; ABTAHI, A. Fuzzy multi-objective optimization model for sustainable reverse logistics network design. Ecological indicators, 2016, Vol.67, pp.753-768. 
INSTITUTO DE PESQUISA ECONÔMICA APLICADA, IPEA, 2018. Nota Técnica IV - Crescimento e Produtividade da Agricultura Brasileira de 1975 a 2016.

Disponível em:

http://repositorio.ipea.gov.br/bitstream/11058/8326/1/cc38_nt_crescimento_e_producao _da_agricultura_brasileira_1975_a_2016.pdf. Acesso em: 08 mai. 2019.

INSTITUTO NACIONAL DE PROCESSAMENTO DE EMBALAGENS VAZIAS INPEV. Preservar o campo limpo. Disponível em <http://www.inpev.org.br/sistemacampo-limpo/artigos/preservar-o-campo-limpo>. Acesso em 25 mai. 2017.

INSTITUTO NACIONAL DE PROCESSAMENTO DE EMBALAGENS VAZIAS INPEV. Relatório de sustentabilidade 2016. Disponível em http://inpev.org.br/Sistemas/Saiba-Mais/Relatorio/inpEV_RS2016.pdf. Acesso em 10 jan. 2018.

KHOR , K. S.; UDIN , Z. M. Reverse logistics in Malaysia: Investigating the effect of green product design and resource commitment. Resources, conservation, and recycling, 2013, Vol.81, pp.71-80.

KLAPALOVÁ, A. Reverse logistics policy - differences between conservative and innovative reverse logistics management. Acta Universitatis Agriculturae et Silviculturae Mendelianae Brunensis, 2013, Vol.61(7), pp.2285-2294.

KLAPAlOVÁ, A. Reverse logistics and 3PL in the Czech Republic. Acta Universitatis Agriculturae et Silviculturae Mendelianae Brunensis, 2012, Vol.60(7), pp.163-170.

LABINAS, A. M.; ARAUJO, M. C. de. Reverse logistics system and the role of government oversight for preservation of water and soil quality: the case of pesticide empty containers. Rev. Ambiente e Água vol. 11 n. 4, Taubaté, p. 759-762, Oct. / Dec. 2016.

LADEIRA, W. J.; MAEHLER, A. E.; NASCIMENTO, L. F. M. Reverse logistics of agricultural pesticides: factors that influence the environmental awareness of Gaucho farmers and miners. Revista de Economia e Sociologia Rural, 2012, Vol.50(1), pp.157-174.

LOPES, C. A.; CRIPA, M. C. ALVES, A. J. S. SEGANTIN, J. A. Implantação da logística reversa de embalagens de agrotóxicos vazias: um estudo em uma pequena propriedade rural no Noroeste paulista. Revista Conbrad Maringá, 2017, v.2, n.1, p. 195-215.

MANOMAIVIBOOL, P.; VASSANADUMRONGDEE, S. Extended producer responsibility in Thailand prospects for policies on waste electrical and electronic equipment. Journal of Industrial Ecology, v. 15, n. 2, p. 185-205, 2011. 
MARTINS, G. A. de M.; SOUZA, M. T. S. de. Gestão da Cadeia de Suprimentos Verde: a influência das Embalagens industriais em programas de logística reversa para a gestão de resíduos sólidos. In: XVI Simpósio de Administração da Produção, Logística e Operações Internacionais. Anais. São Paulo: FGV, 2013. CD-ROM.

MILICHOVSKÝ, František. An Impact of Reverse logistics Activities on Marketing Communication. Acta Universitatis Agriculturae et Silviculturae Mendelianae Brunensis, January 2017, Vol.65(2), pp.669-678.

OLIVEIRA, A. L. de; CAMARGO, S. G. C. de; Logística reversa de embalagens de agroquímicos: identificação dos determinantes de sucesso. Interciencia, 2014, Vol.39(11), pp.780-787.

OLIVEIRA, M. M, de; SABONARO, D. Z. Logística reversa e o processo de destinação das embalagens vazias de agrotóxico. Revista da Universidade Vale do Rio Verde, 2016, Três Corações, v. 14, n. 2, p. 377-383.

ONU. População mundial atingiu 7,6 bilhões de habitantes. 2017. Disponível em https://news.un.org/pt/story/2017/06/1589091-populacao-mundial-atingiu-76-bilhoesde-habitantes. Acesso em 28 abr. 2018.

PEREIRA, R. de M.;, ARAUJO, M. C. de;, LABINAS, A. M. O conhecimento de produtores rurais do município de Arealva, SP, Brasil sobre as regras de uso dos agrotóxicos. Ambiente \& Água - An Interdisciplinary Journal of Applied Science, vol. 11, 2016, pp. 1207-1216 Universidade de Taubaté Taubaté, Brasil Disponível em: http://www.redalyc.org/articulo.oa?id=92852596016. Acesso em: 23 mar. 2018.

Portal de Periódicos CAPES/MEC. 2018. Histórico 1990-2000: A criação do Portal de Periódicos.

PUCHE, P. El Veneno nuestro de cada día. Ecodebate. Revista Sin Permiso, 2013, V 1, pp. 1-6. Disponível em: https://www.ecodebate.com.br/2013/10/24/el-venenonuestro-de-cada-dia-una-epidemia-mundial-por-paco-puche/. Acesso em: 11 jan. 2018.

RODRÍGUEZ, S.; DAVID, J.. Diseño de una red de logística inversa: caso de estudio Usochicamocha - Boyacá. Ingeniería y Ciencia, 2017, Vol.13 (26), p.91-114.

SANTOS, H. P. J. dos; CORTEZ, R. M.; PENEDO, N. S. T.; LIMA, N. C.; SOUZA, G. H. S. de; SILVA, T. E. E. de; QUEIROZ, J. V.; MARTINS, E. S. Materials management: a reverse logistics case of agrotoxics empty containers in a sugar and alcohol company. European Scientific Journal, 2013, Vol.9(26), pp.76-85.

SHIBAO, F. Y.; MOORI, R. G.; SANTOS, M. R. dos. A logística reversa e a sustentabilidade empresarial. In: XIII Seminário de Administração. ISSN 2177.3866. São Paulo, 2010. Disponível em: http://ucbweb2.castelobranco.br/webcaf/arquivos/114487/11297/A_LOGISTICA_REV ERSA_E_A_SUSTENTABILIDADE_EMPRESARIAL.pdf. Acesso em: 13 abr. 2018. 
SILVA, J. D.; CONTRERAS, E. D.; Simulación de un proceso de logística inversa: recolección y acopio de envases y empaques vacíos de plaguicidas. Entre Ciência e Ingeniería, 2015, Vol.9 (18), p.16-23.

SISTEMA NACIONAL DE INFORMAÇÕES SOBRE SANEAMENTO - SNIS (2017). Diagnóstico anual de Resíduos Sólidos. Disponível em:

http://www.snis.gov.br/diagnostico-residuos-solidos. Acesso em: 24 mai. 2017.

RICO, G. K.; CAVICHIOLI, F. A. Análise geral do uso de agrotóxicos no Brasil. DOI: 10.31510/infa.v15i2.505. Interface Tecnológica, 2018, V. 15 n. 2 (2018), pp. 426-435. Disponível em:

https://revista.fatectq.edu.br/index.php/interfacetecnologica/article/view/505/330. Acesso em: 08 mai. 2019.

SINDIVEG. Sindicato Nacional da Indústria de Defesa Vegetal. Consumo de agrotóxicos no Brasil. Disponível em: http://sindiveg.org.br/estatisticas-dosetor/. Acesso em: 09 mai. 2019.

ŠKAPA, R. Formalized Planning and Its Connection With the Development of Reverse logistics: the Case of Services, Acta Universitatis Agriculturae et Silviculturae Mendelianae Brunensis, 01 January 2014, Vol.62(4), pp.749-755

ŠKAPA, R. Reverse logistics in the Czech Republic: Barriers to development. Acta Universitatis Agriculturae et Silviculturae Mendelianae Brunensis, 2011, Vol.59(4), pp.363-370.

VALLE, R.; SOUZA, R. G. Logística Reversa: processo a processo. São Paulo: Atlas, 2014.

VEIGA, M. M. Analysis of efficiency of waste reverse logistics for recycling. Waste Management \& Research, 2013, Vol.31(10_suppl), pp.26-34.

WAICHMAN, A. V. A problemática do uso de agrotóxicos no Brasil: a necessidade de construção de uma visão compartilhada por todos os atores sociais. Rev. Bras. Saúde Ocupac, 2012, V. 37, pp. 17-50.

WANG, F.; HUISMAN, J.; MESKERS, C. E.; SCHLUEP M.; STEVELS, A.; HAGELÜKEN, C. The Best-of-2-Worlds philosophy: developing local dismantling and global infrastructure network for sustainable e-waste treatment in emerging economies. Waste Management, n.32, pp.2134-2146, 2012.

Recebido em 06/11/2018.

Aceito para publicação em 19/04/2019. 